\title{
Lucrar con ciudades y bienes de otros
}

\section{Profit with cities and goods of others}

\author{
Brossat, Ian (20i9), Airbnb. La ciUdad uberizada, Pamplona, \\ KaTAKRAK LUBURUAK, I6O PP., ISBN: 978-84-I6946-25-9
}

En los últimos años, el capitalismo de plataformas digitales ha encontrado una nueva y creciente fuente de lucro a través de la oferta de servicios de alojamiento turístico, transporte de personas y mercancías, así como la entrega de productos a domicilio, que se suma al consumo, comunicación y entretenimiento en teléfonos, computadoras y pantallas. Este nuevo mercado se concentra particularmente en las ciudades, donde vive la mayor parte de la población del mundo.

La pandemia COVID 19 prácticamente paralizó el negocio del alojamiento turístico; en cambio, las plataformas digitales de comunicación, entretenimiento y entrega de productos a domicilio (al que se sumaron las cadenas de supermercados) incrementan colosalmente sus ganancias con una población confinada en su vivienda y temerosa de contagiarse por el contacto social. Más allá del futuro del turismo y de Airbnb, el libro que aquí comentamos devela cómo bajo el discurso de la 'economía colaborativa', una plataforma digital que ha monopolizado la oferta de alojamiento turístico explota el trabajo y los bienes de otros, lucra con las ciudades, evade el pago de impuestos, canibaliza barrios tradicionales y multiplica sus ganancias en mercados financieros.

Ian Brossat, autor de este libro que se reseña, fue teniente alcalde de París y responsable directo de la vivienda en la capital francesa entre 2014 y 2018. Desde esta posición, con documentos y evidencias de primera mano, este joven militante del Partido Comunista Francés expone cómo, en calidad de funcionario público, lidió para regular a las plataformas digitales que ofertan (ir)regularmente alojamiento turístico, mercantilizan la vivienda y destrozan la vida de los barrios y la ciudad. La preocupación de este joven comunista contra la mercantilización de las ciudades francesas se manifiesta en su libro París no está en venta. Propuestas contra la especulación, el cual publicó en 2013. En su más reciente libro, Brossat expone evidencias contundentes de cómo las plataformas digitales trasnacionales 
lucran con ciudades que no son suyas, realizan colosales negocios a nombre del desarrollo, depredan la economía local y encarecen los barrios.

\section{Desmitificando la 'economía compartida'}

El discurso casi altruista que despliega Airbnb en sus estrategias de marketing es evidenciado críticamente en este libro: fomentar ingresos de los hogares a través de compartir su vivienda, el intercambio humano y cultural, el apoyo mutuo entre quien busca y quien ofrece alojamiento temporal, la autenticidad de los encuentros en viviendas y barrios tradicionales, la construcción de la comunidad de viajeros, la confianza entre desconocidos, el alojamiento personalizado que difiere de la oferta estandarizada de los hoteles. Aquí, quien oferta el alojamiento es presentado no como un rentista (por necesidad, gusto o interés), sino como un 'anfitrión' hospitalario sin ánimo de lucro. Así, en el país galo esta plataforma desplegó una campaña mediática que decía "Francia comparte su barrio y construye su futuro".

Sin embargo, este libro demuestra que prácticamente nada de eso ocurre. Se trata de una estrategia de marketing que invisibiliza el verdadero negocio de la plataforma. Las habitaciones que se alquilan en viviendas habitadas no rebasan el 10\% de la oferta. En cambio, la gran mayoría son departamentos y edificios deshabitados cada vez más estandarizados, cuyos propietarios son agentes y empresas inmobiliarias internacionales que se montan en este negocio. Es decir, no es 'gente real' quien alquila esos departamentos, sino agentes inmobiliarios. Podemos agregar que el colectivo que construyó la página web Insideairbnb.com claramente demuestra esto: la oferta se integra de edificios completos deshabitados ubicados en áreas turistificadas. En este mismo sentido, Brossat destaca que Airbnb Plus firmó un convenio de colaboración con la cadena Chateaux \& Hotels Collection para promover una nueva oferta de alojamiento alternativo de lujo.

En el pasado ya existían oferentes y demandantes de alojamiento temporal o turístico que directamente pactaban sin intermediarios. Sin embargo, internet ha permitido industrializar y monopolizar este tipo de servicios y lucrar a través del cobro de comisiones a la oferta y la demanda. Aquí, agrego que se desvanece otro mito de la democratización del uso de internet que promovía acercar oferentes y demandantes a la gente sin intermediarios en relaciones horizontales. Las plataformas digitales son intermediarias en estos múltiples servicios y cobran comisiones por ello.

En 2012 Airbnb abrió una oficina en París y para 2016 esta ciudad se convirtió en el 'primer destino' de la plataforma. Además, Airbnb presume estar en más de 190 países, unas 65,000 ciudades y tener 150 millones 
de usuarios y más de tres millones de alojamientos... pero la plataforma no es propietaria de uno solo de ellos. Su capital estaría -según Brossatvalorado en 26 mil millones de euros y en 2017 tuvo ingresos por 2600 millones, pero en Francia, en 2015, pagó impuestos por 69,168 euros. Es decir, esta empresa evade el pago de impuestos. Airbnb estableció su domicilio fiscal europeo en Irlanda, donde paga $12.5 \%$ de impuestos, pues en Francia tendría que pagar 33 por ciento.

Desde su origen, esta plataforma digital se ha articulado a inversionistas de riesgo y cotiza acciones en mercados financieros. Además, lo 'colaborativo' de esta economía se basa en la extracción de rentas a los bienes y servicios de la gente, pues los oferentes y demandantes que alimentan capital a esta plataforma no participan en la toma de decisiones y mucho menos en los dividendos que ésta obtiene en los mercados financieros. La plataforma difunde además que genera riqueza en las ciudades donde opera. Sin embargo, es preciso aclarar que ningún alojamiento que se ofrece en la plataforma es de su propiedad.

Adicionalmente, Airbnb prometía que quienes alquilan en Francia recuperaran su ganancia sin declarar al fisco a través de una tarjeta recargable de crédito emitida en Gibraltar, paraíso fiscal. Legisladores franceses quisieron prohibir esa tarjeta, pero la correlación de fuerzas en el gobierno francés lo evitó. Aquí, Brossat da cuenta de la capacidad de lobby que tiene esta plataforma en los gobiernos locales, nacionales y en la comunidad europea. En Francia, Airbnb se alió con sus competidores (Home Away, Booking, Clé Vacances, Tripadvisor, etcétera), para 'retorcer las leyes' y continuar depredando la economía local. Airbnb se opone a transparentar sus servicios, no informa públicamente de sus negocios y pone trabas a la regulación del mercado de alojamiento turístico. Así, en un momento convencieron a la Secretaría de Economía Digital de las bondades de los inversionistas innovadores e incluso un representante nacional pidió alojar a los diputados nacionales en Airbnb para 'abaratar costos' al congreso nacional.

\section{La canibalización de los barrios y la vivienda}

En ciudades turísticas como París, Venecia y Barcelona, es todo un desafío que los ciudadanos continúen habitando sus barrios, dice Brossat, pues la creciente oferta y demanda de alojamiento turístico impacta el mercado de vivienda. A muchos propietarios les resulta más lucrativo alquilar sus departamentos por más dinero y menores plazos de tiempo, que alquilar a hogares tradicionales en largos periodos, pues en menos tiempo se obtienen las mismas o mayores ganancias. Igualmente, diversos inversionistas compran 
edificios completos para transformarlos en alojamientos turísticos. Brossat da cuenta de que en nueve días de alquiler turístico se puede obtener la ganancia de un mes completo. Así que los propietarios desalojan a sus tradicionales inquilinos y convierten esas viviendas en alojamiento turístico. Así, ésta y otras plataformas de alojamiento están privando a los vecinos del barrio de la posibilidad de continuar residiendo allí, igual que a otros interesados en alojarse en ellos. El negocio del alojamiento turístico penetra hasta en la vivienda social.

Brossat dice que en París oficialmente 3\% de las viviendas se ofertan en Airbnb, pero en el distrito VII el porcentaje se incrementa a $17.4 \%$, mientras que en Les Marais había más de 2000 anuncios y los alojamientos en promedio se ocupan 199 noches al año. De manera sintomática, se han despoblado los distritos donde hay más alojamientos turísticos: entre 2010 y 2015 más de 37,000 habitantes desalojaron estos espacios. Se trata de un problema compartido en otras ciudades europeas; por ejemplo, en el barrio gótico de Barcelona entre 2006 y 2015 casi la mitad de sus habitantes cambió su residencia, mientras que en Venecia $60 \%$ de su población en las últimas dos décadas se mudó a otros espacios. En esta ciudad italiana había, en 2018, 6000 anuncios activos de Airbnb a un costo promedio de 130 euros por noche; además, $75 \%$ de los anuncios son edificios completos, no cuartos, viviendas o edificios habitados.

La gentrificación no sólo alcanza la vivienda, sino los comercios y servicios de barrio. En los barrios turistificados y gentrificados, los visitantes de corta estancia no consumen lo mismo ni de la misma forma que los residentes tradicionales que viven y trabajan en la ciudad. Así que las tradicionales tiendas de productos y servicios de proximidad son sustituidas paulatinamente por tiendas de souvenirs, boutiques de lujo, servicios gastronómicos y supermercados. La diversidad comercial y de servicios es paulatina y brutalmente erosionada: Airbnb vende lugares auténticos, pero contribuye a uniformizar el mundo. "Los residentes de esos barrios deben sentirse como los indios en el lejano oeste, a quienes arrebataron su propia tierra", afirma el autor. Otro ejemplo citado es el del bello barrio de Montmartre, donde oficialmente no hay hoteles, pero la plataforma ofrece edificios completos transformados en alojamientos turísticos clandestinos y el barrio - en palabras de Brossat - parece Disneylandia con las nuevas tiendas y comercios que emulan la belle époque, los cantantes en calles y bares que interpretan a Edith Piaf y los organilleros que tocan chansons.

En este mismo sentido, el libro denuncia muchos conflictos entre los escandalosos visitantes de vacaciones y los residentes que trabajan en la ciudad: ruidos, fiestas nocturnas, basura, fumadores, borrachos que arman trifulcas, desgaste de elevadores y áreas comunes por uso intensivo, hasta destrozos en los departamentos. Para Brossat, las plataformas digitales de 
alojamientos turísticos agravan conflictos preexistentes y hacen que muchos vecinos emigren hacia barrios más tranquilos.

\section{Precariedad laboral}

La plataforma crea empleos indirectos, pero precarios. De hecho, las plataformas digitales casi no tienen personal y los empleos que se generan en torno al alojamiento turístico son temporales y de bajos salarios: vigilantes, conserjes, servicio de limpieza, lavanderas, choferes, repartidores. Aquí no hay ningún tipo de prestación laboral ni seguridad social. Se trata de empleos tipo Uber, donde los choferes se autoexplotan y aportan sus propios autos. Tal vez con el confinamiento obligatorio producido por la pandemia COVID 19 estamos asistiendo a la creación de un nuevo nicho de mercado: la autoexplotación de los trabajadores en su propia casa.

Por otra parte, hay una precaria relación entre el oferente y el usuario que coloca en situación vulnerable a quien alquila frente a daños y destrozos. Ningún contrato oficial vincula al huésped con el anfitrión. En el libro se da cuenta de casos concretos en donde la plataforma ocultó conflictos surgidos por destrozos y daños en departamentos, e intentó privatizar las pérdidas, salvo cuando el conflicto se tornó público. Así, la plataforma explota el trabajo de otros y no asume riesgos ni seguros de ningún tipo.

\section{Gobiernos locales versus empresa trasnacional}

En 2016, a pesar de la oposición de las plataformas digitales de alojamiento temporal, la alcaldía de París reguló parcialmente los alojamientos turísticos temporales: alquiler de alojamientos habitados hasta 120 noches al ańo, de lo contrario, se debía cambiar el uso del suelo a comercial y pagar los impuestos respectivos; de tal manera que al llegar al tope se desactivan esos anuncios. También se estipuló que se duplicaría el monto de la multa para viviendas alquiladas de manera clandestina, de 25,000 a 50,000 euros; se creó un número de registro obligatorio de las viviendas que se ofrecían; asimismo se debía transparentar la identidad de los huéspedes cuando las autoridades lo demandaran. En este mismo sentido, en 2018 un Tribunal de Casación falló que el alquiler turístico de una vivienda es contrario al destino residencial del inmueble, lo que constituye un antecedente importante para defender el derecho a la vivienda.

El libro destaca la cooperación entre gobiernos locales de ciudades europeas que luchan contra las viviendas turísticas por sus nefastos efectos 
en las ciudades: la desaparición de la vida del barrio, el alza de precios de los alquileres y la erosión del comercio tradicional. Así, se cita que, en Barcelona, que recibe ocho millones de turistas al año, se emitió una moratoria en 2015 para el otorgamiento de licencias de viviendas turísticas: aquí, oficialmente se permiten 10,000 licencias, pero extraoficialmente llegan a 75,000 alojamientos, y en 2016 se multó a Home Away y a Airbnb.

\section{Plataformas digitales asaltan las ciudades}

En este agudo libro, el autor nos dice que Airbnb es sólo la punta del iceberg, pues Google, Apple, Facebook, Amazon, Uber, Netflix, etcétera, tienen las "manos sobre la ciudad". Estas plataformas digitales tienen millones de clientes, manejan millones de datos y se despliegan en las ciudades con nuevos productos, donde vive la mayor cantidad de consumidores.

Este tipo de negocios lo inició IBM con la Smart City y su software que supuestamente gestiona de manera eficaz y eficiente cada vez más servicios de y en las ciudades: transporte, tráfico, seguridad, etcétera. Sin embargo, ahora Uber vende estudios sobre traslados particulares y Google vende big data que 'conoce' los gustos personales de sus millones de usuarios.

Las sedes de estas empresas también se mercadean como innovaciones urbanas y ciudades del futuro: Ciudad Google en Mountain View, Silicon Valley; Apple Park, Airbnb, Uber y Twitter en San Francisco; y Amazon en Seattle. En Toronto, la empresa Sidewalk creó en 2017 una ciudad modelo, donde los habitantes tienen una cuenta de usuario y hay miles de sensores y cámaras que registran, analizan y 'mejoran' los flujos. Frente al COVID 19, dirán los inversionistas, esos sensores pueden medir la temperatura de las personas para evitar la propagación del contagio.

Para Brossat, la presencia de Airbnb constituye un ataque contra el derecho a la ciudad, porque incrementa los alquileres, mata a los pequeños comercios tradicionales, despuebla los barrios, vacía las escuelas y depreda las relaciones vecinales. Lejos de la economía colaborativa esta empresa oculta sus prácticas depredadoras que se realizan al límite de la legalidad y la moralidad. Este joven comunista insiste que las ciudades son de los ciudadanos, no de los turistas.

\section{Colofón:}

A partir del 1 de junio de 2020 en México se comienza a cobrar 16\% de Impuesto al Valor Agregado (IVA) a las plataformas digitales, cosa que algu- 
nos líderes de opinión consideran como un ataque al libre comercio. Curiosamente se trata de personajes que en el pasado reciente justificaban el cobro del IVA a alimentos y medicinas. Sin embargo, las plataformas digitales no pierden, simplemente trasladan a los consumidores el pago del IVA.

Además, más allá del cobro del IVA en México no hay indicios de regular esta actividad para proteger a la gente, los barrios, la vivienda y el comercio local frente al negocio de las plataformas digitales. Uno de los peores ejemplos lo tenemos en la llamada Casa de la Covadonga, en el centro histórico de la Ciudad de México: este inmueble (declarado Monumento Histórico) fue rehabilitado entre 2000 y 2002 por el Gobierno del Distrito Federal y la Junta de Andalucía para permitir que sus antiguos residentes continuaran viviendo, en condiciones dignas, en el centro histórico. Sin embargo, actualmente cinco de los 36 departamentos que lo integran fueron adquiridos por un propietario y se ofertan en 110 dólares la noche, a través de la plataforma Airbnb. ¿Cómo la vivienda social, altamente subsidiada, se mercantiliza? ¿Por qué la autoridad (en este caso el Instituto de Vivienda de la Ciudad de México) vendió a un particular cinco departamentos de interés social? ¿Ésta es la idea de repoblamiento que han tenido las autoridades locales de 'izquierda' desde el 2000? Brossat nos preguntaría a los mexicanos: ¿De quién es la ciudad? ¿De los ciudadanos o de los turistas y de las plataformas que lucran con bienes que no son suyos?

\section{Referencias}

Brossat, Ian and Baudrier Jacques (2013), Paris n'est pas à vendre: Propositions face à la spéculation, París, Arcane.

Victor Delgadillo

victor.delgadillo@uacm.edu.mx

Profesor-investigador del Colegio de Humanidades y Ciencias Sociales Universidad Autónoma de la Ciudad de México

Victor Manuel Delgadillo Polanco. Doctor en Urbanismo por la Universidad Nacional Autónoma de México (UNAM). Profesor-investigador del Colegio de Humanidades y Ciencias Sociales de la Universidad Autónoma de la Ciudad de México y profesor de asignatura del posgrado en Urbanismo de la UNAM. Integrante del Sistema Nacional de Investiga- 
dores, nivel II. Sus líneas de investigación actuales son centros históricos de América Latina, gentrificación, derecho a la ciudad, patrimonio urbano y políticas urbanas. Entre sus últimas publicaciones como autor destacan: "Metáforas de las ciudades latinoamericanas ¿Conceptos y adjetivaciones importadas, neutras y despolitizadas?, REVISTARQUIS, 8 (2), San José, Universidad de Costa Rica, pp. 49-65 (2019) y "Turismo y patrimonio. Cincuenta años de 'rescate' del Centro Histórico de la Ciudad de México", Estudios Críticos del Desarrollo, 8 (14), Zacatecas, Universidad Autónoma de Zacatecas, pp. 141-170 (2018); como co-coordinador, Mercados de abasto: Patrimonio, turismo, gentrificación, Roma, Aracne Editores (2020). 